\title{
Stable COPD: predicting benefit from high-dose inhaled corticosteroid treatment
}

\author{
R. Leigh*, M.M.M. Pizzichini*,\#, M.M. Morris*, F. Maltais", \\ F.E. Hargreave* and E. Pizzichini*,\#
}

ABSTRACT: The role of inhaled corticosteroids in the management of chronic obstructive pulmonary disease (COPD) remains controversial. The purpose of this study was to evaluate whether sputum eosinophilia (defined as eosinophils $\geqslant 3 \%$ ) predicts clinical benefit from inhaled corticosteroid treatment in patients with smoking-related clinically stable moderate-to-severe COPD.

Forty consecutive patients with effort dyspnoea (mean age 67 yrs; 52 pack-yr smoking history; post-bronchodilator forced expiratory volume in one second $\left(\mathrm{FEV}_{1}\right)<60 \%$ predicted, consistent with moderate-to-severe smoking-related chronic airflow limitation) were enrolled. Subjects were treated with inhaled placebo followed by inhaled budesonide (Pulmicort Turbuhaler $1,600 \mu \mathrm{g}$. day $^{-1}$ ), each given for 4 weeks. While the treatment was single-blind (subject level), sputum cell counts before and after treatment interventions were double-blind, thus removing bias. Outcome variables included spirometry, quality-of-life assessment and 6-min walk test.

Sputum eosinophilia was present in $38 \%$ of subjects. In these, budesonide treatment normalised the eosinophil counts and, in comparison to placebo treatment, resulted in clinically significant improvement in the dyspnoea domain of the disease-specific chronic respiratory questionnaire ( 0.8 versus 0.3$)$ and a small but statistically significant improvement in postbronchodilator spirometry (FEV1 $100 \mathrm{~mL}$ versus $0 \mathrm{~mL} ; \mathrm{p}<0.05$ ).

In conclusion, sputum eosinophilia predicts short-term clinical benefit from high-dose inhaled corticosteroid treatment in patients with stable moderate-to-severe chronic obstructive pulmonary disease.

KEYWORDS: Airway inflammation, chronic obstructive pulmonary disease, eosinophils, induced sputum, inhaled corticosteroids

$\mathbf{T}$ he role of inhaled corticosteroids (ICS) in the management of stable chronic obstructive pulmonary disease (COPD) remains controversial $[1,2]$. The results of several large, multicentre randomised controlled trials [3-7] suggest that there may be a small clinical benefit from ICS treatment, particularly in patients with more severe disease. Nonetheless, despite the lack of compelling evidence for their use, many COPD patients are treated with regular ICS therapy [8]. COPD is heterogeneous $[9,10]$, and there are likely to be subgroups of patients who will benefit from ICS treatment. It is probable that such benefit within phenotypic subgroups will be lost when the data from large randomised controlled trials are analysed within a heterogeneous study population.

As yet, no useful predictor of clinical response to ICS treatment in patients with COPD has been identified [11, 12]. Having considered previous studies showing that sputum eosinophilia predicts short-term clinical benefit from prednisone (or prednisolone) treatment in patients with COPD $[13,14]$, the present authors reasoned that sputum eosinophilia may also be a valid predictor of clinical benefit from ICS treatment. The purpose of this study was therefore to determine whether sputum eosinophilia (defined in this study as eosinophils $\geqslant 3 \%$ ) is useful in predicting clinical benefit from treatment with high-dose budesonide ( $800 \mu \mathrm{g}$ twice daily), given for 4 weeks in patients with established, smoking-related, clinically stable moderate-to-severe COPD.

\section{SUBJECTS, METHODS AND STUDY DESIGN}

\section{Subjects}

From the respiratory clinics of three university centres, 44 adults with a physician diagnosis of COPD [15] and the following characteristics were consecutively recruited. All subjects were $\geqslant 40 \mathrm{yrs}$ old, current or ex-smokers of $\geqslant 20$ pack-yrs, and had effort dyspnoea and moderate-to-severe
AFFILIATIONS

*Firestone Institute for Respiratory Health, St. Joseph's Healthcare and McMaster University, Hamilton, ON, and

'Centre de recherche, Hôpital Laval, Institut universitaire de cardiologie et de pneumologie de l'Université Laval, $Q C$, Canada.

${ }^{\text {\#}}$ NuUPAIVA (Nucleo da Pesquisa em Asma e Inflamação das Vias Aéreas) - Universidade Federal de Santa Catarina, Florianopólis, Brazil.

\section{CORRESPONDENCE}

E. Pizzichini

NUPAIVA

Hospital Universitário

Universidade Federal de Santa

Catarina

Florianópolis

Santa Catarina 88040390

Brazil

Fax: 55482347711

E-mail: pizzichi@matrix.com.br

Received:

June 202005

Accepted after revision:

January 022006

SUPPORT STATEMENT

The study was supported by a grantin-aid from AstraZeneca, Sweden. R. Leigh was the recipient of a Canadian Institutes for Health Research Fellowship. F. Hargreave is supported by the Father Sean O'Sullivan Research Centre. E. and M.M.M. Pizzichini were recipients of CNPq (Conselho Nacional de Pesquisa) Brazil research awards. 
COPD (Global Initiative for Chronic Obstructive Lung Disease stage II or III) as indicated by a post-bronchodilator forced expiratory volume in one second (FEV1)/slow vital capacity (SVC) of $<70 \%$ and an FEV $1<60 \%$ predicted. Partial post-bronchodilator airflow reversibility was not an exclusion criterion since the objective of the study was to investigate the predictive value of sputum eosinophilia. The subjects were stable on treatment with salbutamol or ipatropium; none had used either inhaled corticosteroids or prednisone for $\geqslant 2$ months. The study was approved by the research ethics boards of each study site, and all subjects gave written informed consent before participating in the study.

\section{Study design}

This was a three-centre study, with sequential placebo followed by budesonide treatment crossover trial. While the treatment was single-blind (subject level), bias was removed by double-blinding of induced sputum cell counts on which the analysis was based. There were five or six visits in the morning, within $2 \mathrm{~h}$ of visit 1 . At the first visit, subject characteristics were documented (including spirometry, quality of life, a 6-min walk test and induced sputum examination) and subjects were instructed to continue their pre-study inhaled bronchodilator(s) as needed, and to record their use, plus symptoms, on a diary card. The walk test was repeated at a second and third visit, within a 7-day period to ensure its optimum performance. At visit 3, spirometry and induced sputum examination was repeated and the subjects were started on inhaled placebo Turbuhaler ${ }^{\circledR}$ (AstraZeneca, Lund, Sweden), two inhalations twice daily, for 4 weeks. At visit 4 this treatment was changed to inhaled budesonide (Pulmicort Turbuhaler ${ }^{*}$; AstraZeneca), $400 \mu \mathrm{g}$, two inhalations twice daily (total daily dose $1,600 \mu \mathrm{g}$ ) for a further 4 weeks. Finally, at visit 5 , in those subjects who were agreeable, prednisone $30 \mathrm{mg}$ daily was given for 14 days. Outcome measurements of preand post-bronchodilator FEV1, quality-of-life assessment, 6min walk test and induced sputum cell counts were repeated at these visits and after prednisone treatment.

\section{Methods}

Treatment allocation was concealed from subjects for the duration of the study. The medications were supplied by AstraZeneca (AstraZeneca Inc., Mississauga, ON, Canada) and were independently packaged and labelled by the hospital pharmacy. Placebo Turbuhalers ${ }^{\circledR}$ were identical in appearance and labelling to Pulmicort Turbuhalers ${ }^{\circledR}$, so patients were unable to determine treatment allocation. At the start of each treatment period, each subject was given a new coded Turbuhaler ${ }^{\circledR}$; their inhalation technique was checked and corrected if necessary. At the end of each treatment period, study medication was returned and compliance was monitored by counting the number of remaining Turbuhaler ${ }$ doses.

Subject characteristics were documented by questionnaire. Effort dyspnoea was assessed with the Medical Research Council dyspnoea scale [16]. Allergy skin tests were performed using the modified prick technique [17] with common allergen extracts and a negative and positive control. Pre- and postsalbutamol $(400 \mu \mathrm{g}) \mathrm{FEV} 1$, SVC and inspiratory capacity (IC) were measured according to American Thoracic Society specifications [18], after withholding inhaled $\beta$-agonists or ipratropium bromide for $\geqslant 6 \mathrm{~h}$. Measurements obtained at visit 1 were recorded as baseline. Bronchodilator reversibility was considered to be present when the FEV1 increased by $200 \mathrm{~mL}$ and $>10 \%$ from predicted value [11]. The quality-oflife assessment was measured with the disease-specific Chronic Respiratory Questionnaire (CRQ) [19]. For the Brazilian and French-Canadian centres, across-cultural adaptation of the questionnaire was developed and validated according to standard criteria [20]. The CRQ measured four domains (dyspnoea, fatigue, emotion and mastery, using a 7point Likert scale) and a global CRQ score was obtained from the sum of the four domains. The minimum change indicating a clinically important benefit was 2 points in global score and 0.5 points in each domain score. The 6-min walk test was performed according to standardised protocol [21] at each of the first three visits to control for a possible learning effect; the longest distance walked on any of these visits was used as the baseline measurement [22]. Sputum was induced with normal or hypertonic saline, then selected from expectorate and treated with dithiothreitol using the methods of PIZZICHINI and co-workers [13, 23]. It was examined for colour, cell viability with trypan blue, squamous cell contamination, total cell count in a haemocytometer, and differential cell count on Wright stained cytospins. Normal cell counts were taken from BELDA et al. [24]. The cut-off point for normal eosinophils is $\leqslant 2 \%$ and that which usually indicates improvement with steroid treatment is $\geqslant 3 \%$ [13]. Sputum cell counts performed at visits 1 and 2 were repeatable (intra-class correlation coefficient 0.9) and cell counts obtained at visit 2 were recorded as baseline. Quality assurance between study centres was assessed by interobserver repeatability, which was $>0.9$.

\section{Analysis}

In a previous study [13], the present group confirmed that a sample size of 18 subjects with moderate-to-severe COPD, with and without eosinophilia, was sufficiently powered to detect statistically significant differences in dyspnoea scores, quality of life and FEV1 measurements following prednisone treatment. Using data from that study, the authors calculated $a$ priori that a sample size of 40 subjects would provide sufficient power $(\geqslant 80 \%)$ to detect a minimally important difference of $200 \mathrm{~mL}$ (SD $300 \mathrm{~mL}$ ) in FEV1 between the treatment groups in the present study.

Descriptive statistics were used to summarise the baseline characteristics of the study patients. The results were expressed as mean $\pm \mathrm{SD}$ if the data were normally distributed and as median (interquartile range) if the data were nonnormally distributed. Repeated measures ANOVA were used to test for the effects of treatment on the dependent variables, with post hoc analysis used to identify the source of significant variation when present. All comparisons were two-tailed and p-values $<0.05$ were considered significant.

\section{RESULTS}

Of the 44 subjects enrolled in the study, four were excluded from the final analysis; two developed infective exacerbations during the study, one was non-compliant with treatment, and one died of an acute coronary thrombosis (confirmed at autopsy) during placebo treatment. The baseline characteristics 
of the remaining 40 subjects were stratified by sputum eosinophil counts (tables 1 and 2). Fifteen (38\%) subjects had sputum eosinophilia $\geqslant 3 \%$, and were more likely to be male and to have a greater degree of chronic airflow limitation compared to patients without sputum eosinophilia. There was no difference in other sputum characteristics between the two groups. Sputum eosinophilia did not predict the presence of atopy or of bronchodilator reversibility; 16 (40\%) subjects had bronchodilator reversibility $>10 \%$ pred and four $(10 \%)>15 \%$ pred (fig. 1).

The effects of budesonide treatment on sputum cell counts in the eosinophilic and non-eosinophilic groups were examined (fig. 2). In all subjects with sputum eosinophilia, placebo treatment had no effect but budesonide reduced eosinophils to

\begin{tabular}{|c|c|c|c|}
\hline & \multicolumn{2}{|c|}{ Sputum eosinophils } & \multirow[t]{2}{*}{ p-value } \\
\hline & $\geqslant 3 \%$ & $<\mathbf{3} \%$ & \\
\hline Subjects & $15(37.5)$ & $25(62.5)$ & NS \\
\hline Age yrs & $68(55-78)$ & $66(41-86)$ & NS \\
\hline Males & $13(87)$ & $13(52)$ & 0.04 \\
\hline Smoking pack-yrs & $58 \pm 27$ & $49 \pm 24$ & NS \\
\hline Atopic $^{\#}$ & $2(13.3)$ & $5(20)$ & 0.4 \\
\hline Post-BD FEV 1 , \% & $41 \pm 12$ & $56 \pm 13$ & 0.001 \\
\hline Post-BD FEV $1 /$ SVC \% & $37 \pm 8.8$ & $48 \pm 9.6$ & 0.001 \\
\hline$\Delta$ FEV1 after BD \% pred & $7.1 \pm 4.2$ & $8.9 \pm 4.2$ & NS \\
\hline$\Delta \mathrm{FEV}_{\mathbf{1}}>\mathbf{2 0 0} \mathrm{mL}$ after BD & $6(40)$ & $10(40)$ & NS \\
\hline
\end{tabular}

Data are presented as mean $\pm \mathrm{SD}, \mathrm{n}(\%)$ or mean (minimum-maximum). Forced expiratory volume in one second (FEV 1 ) predicted values are from CRAPO et al. [25] and are post-bronchodilator (post-BD). NS: nonsignificant; SVC: slow vital capacity; \% pred: \% predicted. " : one or more positive allergy skin-prick test. NS was considered to be a p-value of $>0.05$.

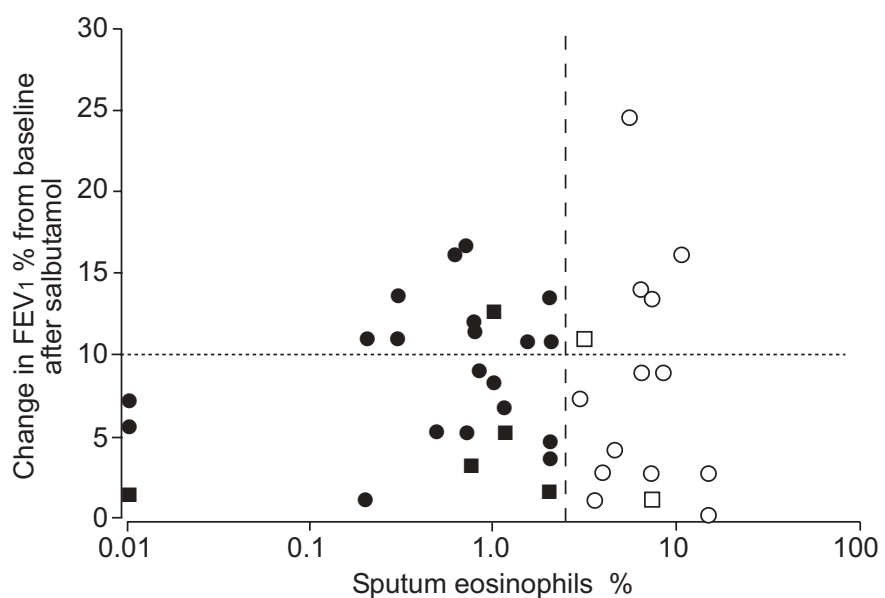

FIGURE 1. Scatter plot showing the relationship between sputum eosinophilia and response to inhaled salbutamol (expressed as a change in forced expiratory volume in one second $\left(\mathrm{FEV}_{1}\right)$ as a percentage of baseline pre-bronchodilator FEV1). Bronchodilator reversibility does not predict sputum eosinophilia. $O$ : patients with sputum eosinophils $\geqslant 3 \%$; $\bullet$ : patients without sputum eosinophilia; $\square$ : atopic patients with sputum eosinophilia; $\mathbf{\square}$ : atopic patients without sputum eosinophilia; - - -: upper limit of normal for sputum eosinophils; $\cdots \cdots \cdots \cdot$. represents clinically important bronchodilator reversibility.

within the normal range $(p<0.001)$. In subjects with no eosinophilia, eosinophils remained within the normal range after both interventions (table 2). Budesonide treatment had no effect on other cell types in either group.

The effects of budesonide treatment on clinical outcome variables were examined. Budesonide produced a small but statistically significant increase in mean and absolute change in post-bronchodilator FEV1 compared with placebo in subjects who had sputum eosinophilia (table 2, fig. 3), as well as in CRQ global and dyspnoea domain scores (table 2, figs 4 and 5). The improvement in CRQ dyspnoea domain score was also

TABLE 2 Changes in outcome variables in patients with and without sputum eosinophilia

Treatment

Sputum eosinophils

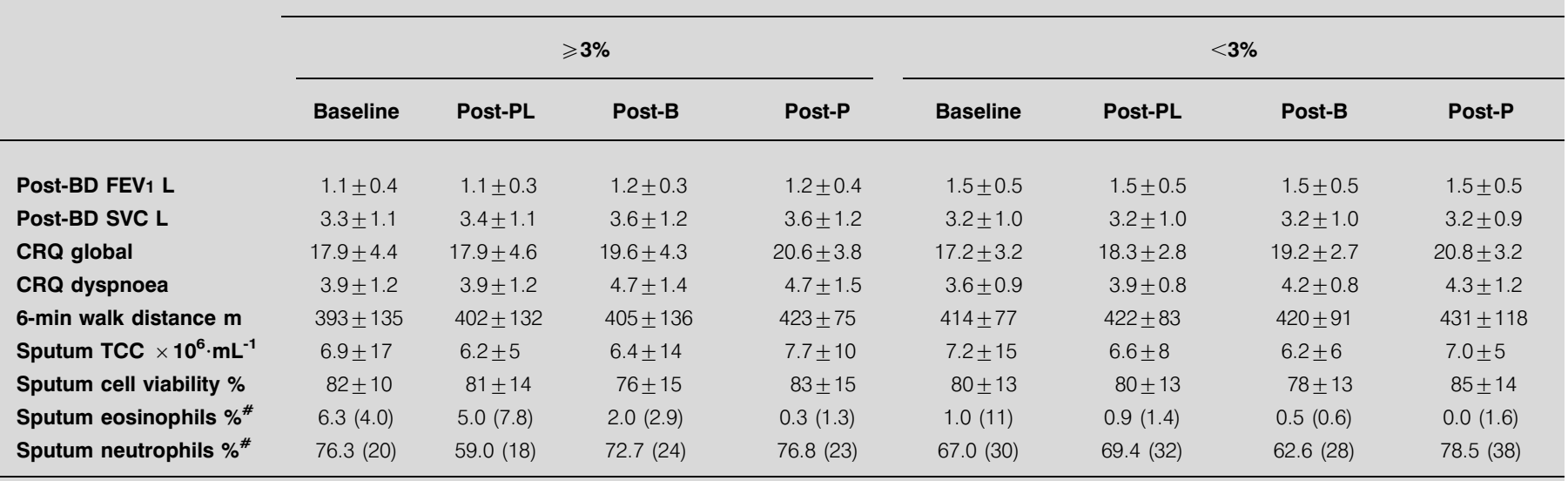

Data presented as mean \pm SD, unless otherwise stated. Post-PL: post-placebo; Post-B: post-budesonide; Post-P: post-prednisone; Post-BD: post-bronchodilator; FEV1: forced expiratory volume in one second; SVC: slow vital capacity; CRQ: Chronic Respiratory Questionnaire; TCC: total cell count. * : results expressed as median (interquartile range), where the interquartile range is the 75 th percentile minus the 25 th percentile. 


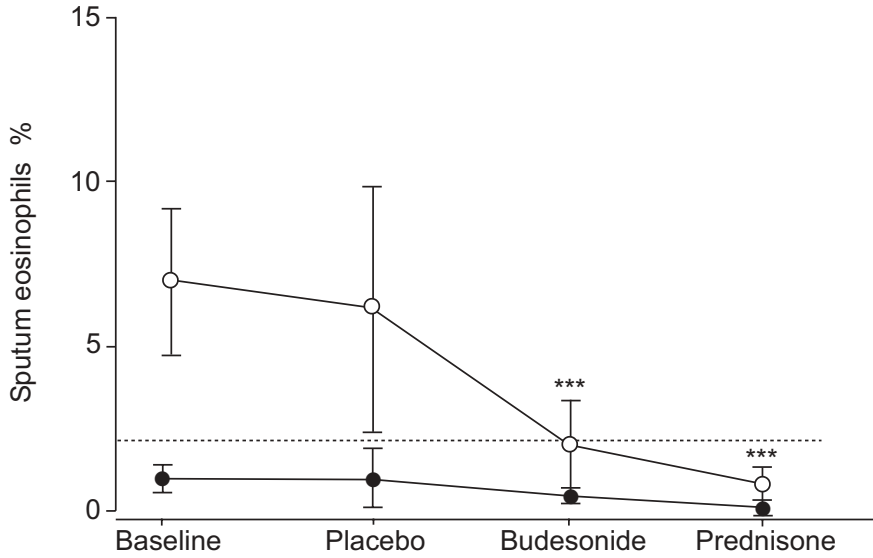

FIGURE 2. Median $\%$ sputum eosinophils in patients with $(\bigcirc)$ and without ( sputum eosinophilia $\geqslant 3 \%$ at baseline and after placebo, budesonide and prednisone treatment. Error bars represent interquartile range. Eosinophilia is reversed by the budesonide treatment. ….... upper limit of normal sputum eosinophils. ${ }^{* *}: \mathrm{p}<0.001$ within group difference for budesonide and prednisone compared to placebo.

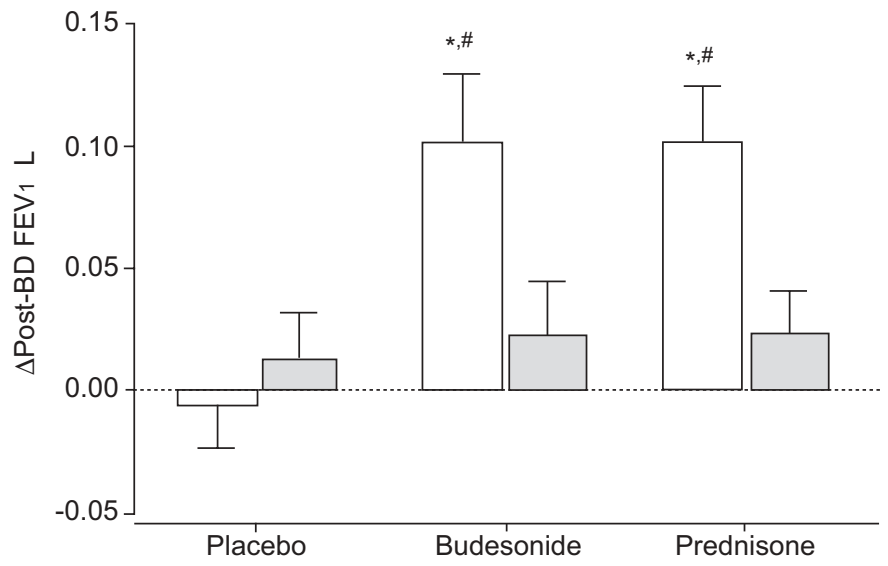

FIGURE 3. Change in post-bronchodilator (post-BD) forced expiratory volume in one second $\left(F E V_{1}\right)$ from baseline after placebo, budesonide and prednisone treatment. Error bars represent SEM. $\square$ : patients with sputum eosinophilia $\geqslant 3 \%$ at baseline; $=$ : patients without sputum eosinophilia; …........ baseline from which change is measured. *: $p<0.05$ for within-group (sputum eosinophilia) differences after budesonide and prednisone treatment compared to placebo; ${ }^{\#}$ : $p<0.05$ for between-group differences.

clinically relevant. Budesonide treatment did not cause any significant increase in the post-bronchodilator SVC or IC in the eosinophilic and non-eosinophilic groups. Also, budesonide did not increase the distance walked during the 6-min walk test.

Thirty-four (85\%) subjects (13 eosinophilic, 21 non-eosinophilic) agreed to participate in the prednisone arm of the study. Prednisone treatment resulted in further reduction of sputum eosinophils to $<1 \%$ in both the eosinophilic $(\mathrm{p}<0.001$ compared to baseline) and non-eosinophilic groups (fig. 2) and a small additional increase in CRQ global scores (figs 3-5). This reached clinical relevance when compared with placebo treatment in subjects with sputum eosinophilia (figs 4 and 5).

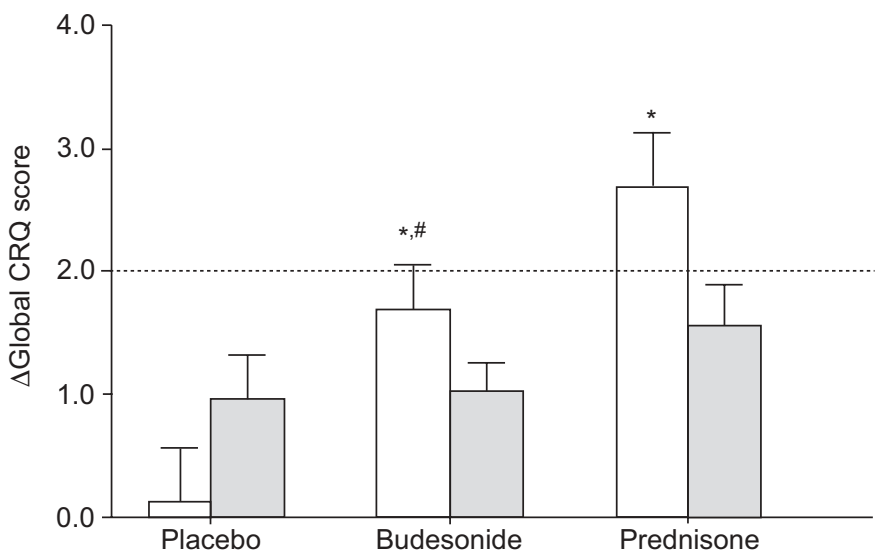

FIGURE 4. Change in global Chronic Respiratory Questionnaire (CRQ) scores from baseline after placebo, budesonide and prednisone treatment. Error bars represent SEM. $\square$ : patients with sputum eosinophilia $\geqslant 3 \%$ at baseline; $\square$ : patients without sputum eosinophilia; $\cdots \cdots \cdot \cdots$. minimally important clinical difference *: $p<0.05$ for within-group (sputum eosinophilia) differences after budesonide and prednisone treatment compared to placebo; ${ }^{*}: p<0.05$ for between-group differences.

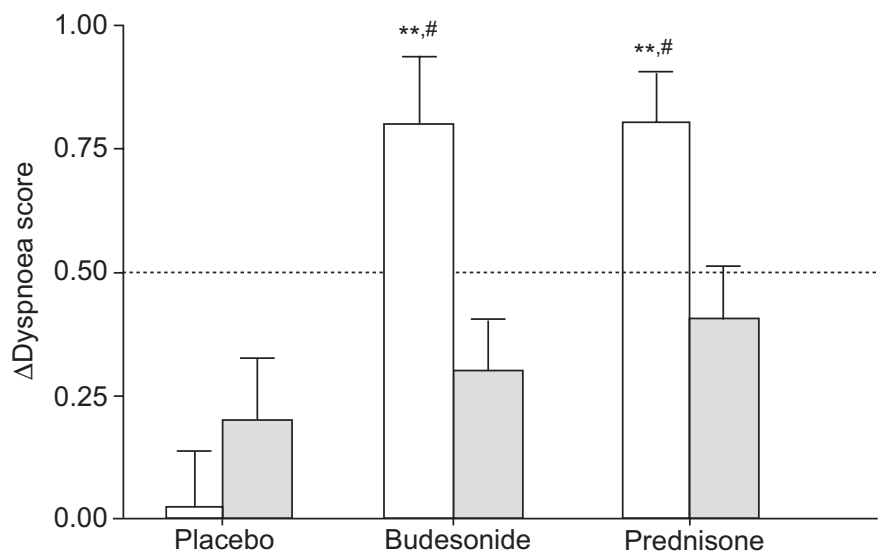

FIGURE 5. Change in dyspnoea Chronic Respiratory Questionnaire (CRQ) scores from baseline after placebo, budesonide and prednisone treatment. Error bars represent SEM. $\square$ : patients with sputum eosinophilia $\geqslant 3 \%$ at baseline; patients without sputum eosinophilia; ........ minimally important clinical difference. $* *$ : $p<0.01$ for within-group (sputum eosinophilia) differences after budesonide and prednisone treatment compared to placebo; $\#$ : $p<0.05$ for between-group differences.

However, the beneficial effects of prednisone were not significantly greater than those achieved with budesonide.

The authors also examined the outcomes in all study participants without categorising them into eosinophilic or non-eosinophilic sub-groups. Budesonide and prednisone resulted in a significant attenuation of sputum eosinophilia $(p<0.01)$ when compared to placebo treatment, but neither treatment had any significant effect on CRQ or FEV1 (table 3).

\section{DISCUSSION}

In this study, treatment with inhaled budesonide 1,600 $\mu \mathrm{g}$. day $^{-1}$ for 4 weeks produced a clinically important and statistically significant effect on dyspnoea during day-to-day 


\begin{tabular}{lcccc} 
TABLE 3 & Changes in outcome variables when all subjects were assessed as a whole group \\
\hline Treatment & Baseline & Post-placebo & Post-budesonide & Post-prednisone \\
\hline & & & & $1.4 \pm 0.5$ \\
Post-BD FEV $\mathbf{~ L ~}$ & $1.3 \pm 0.4$ & $1.4 \pm 0.4$ & $19.4 \pm 3.4$ & $21.0 \pm 0.4$ \\
CRQ global & $17.5 \pm 3.6$ & $18.1 \pm 3.5$ & $4.4 \pm 1.1$ & $4.6 \pm 1.3$ \\
CRQ dyspnoea & $3.7 \pm 1.0$ & $3.9 \pm 0.9$ & $414 \pm 104$ & $430 \pm 117$ \\
6-min walk distance m & $406 \pm 101$ & $414 \pm 103$ & $0.8(1.0)^{*}$ & $0.7(1.4)^{*}$ \\
Sputum eosinophils \% & $1.9(3.7)$ & $1.6(3.2)$ & &
\end{tabular}

Data presented as mean $\pm \mathrm{SD}$, unless otherwise stated. Post-BD: post-bronchodilator; FEV1: forced expiratory volume in one second; CRQ: Chronic Respiratory Questionnaire. *: results expressed as median (interquartile range), where the interquartile range is the 75 th percentile minus the 25 th percentile. ${ }^{*}: p<0.05$.

activities, and a small, statistically significant improvement in post-bronchodilator FEV1 in subjects who had sputum eosinophilia $\geqslant 3 \%$ compared with treatment with inhaled placebo. In contrast, subjects without sputum eosinophilia did not show benefit from inhaled budesonide treatment. These findings suggest that sputum cell counts are a useful measurement in the clinical management of COPD. They provide substantive evidence that sputum eosinophilia predicts clinical benefit from high-dose inhaled corticosteroid treatment.

The results are consistent with previous publications, indicating that sputum eosinophilia is a predictor of clinical benefit from either prednisone or prednisolone treatment in patients with COPD [13, 14], and they extend this knowledge to treatment with high-dose ICS. Sputum eosinophilia is a relatively common finding in patients with clinically stable, moderate-to-severe, smoking-related COPD. It occurred in 38\% of consecutively enrolled subjects in the present study, which is similar to the prevalence reported by others $[13,14,26]$ in similar cohorts of patients. The results differ from those recently reported by BRIGHTLING et al. [26] in similar patients in a randomised, double-blind, crossover trial of inhaled mometasone $800 \mu \mathrm{g}$ daily and placebo, each given for 6 weeks with a 4-week washout period between treatments. The modest dose of mometasone was followed by a small but significant improvement in FEV1 of $0.11 \mathrm{~L}$ only in those patients with sputum eosinophils $>3.9 \%$. However, there was no improvement in CRQ or sputum eosinophils. The latter, when considered in relation to the reduction of eosinophils seen in the present study, suggests that the dose of mometasone and its relative potency were too low to have optimal effects. While it would have been preferable to identify a predictive marker of ICS benefit that would be easier to measure than sputum eosinophilia, neither the presence of atopy alone (as defined by positive allergy skin-prick tests) nor the presence of postsalbutamol reversibility alone were able to predict clinical benefit of inhaled budesonide.

When considering the validity of these results, it is necessary to look at the characteristics of the subjects studied, the study design, the sample size and the outcomes of CRQ and FEV1. Subjects with partial $\beta_{2}$-agonist bronchodilator reversible airflow limitation were not excluded because it is recognised that a proportion of patients with COPD demonstrate significant post-bronchodilator reversibility (i.e. by definition, they also have asthma) [27]. In elderly patients, with a significant smoking history and the presence of moderate-tosevere chronic airflow limitation, the primary clinical diagnosis is still likely to be that of smoking-related COPD, regardless of whether or not there is an additional element of $\beta_{2}$-agonist reversible airflow limitation present. In the current study, all participants were $>40$ yrs and had a smoking history of $>20$ pack-yrs, the vast majority $(>80 \%)$ were non-atopic on allergy skin testing, and they all had objective evidence of persistent chronic airflow limitation after salbutamol. There was no relationship between salbutamol reversibility and sputum eosinophilia, indicating that sputum eosinophilia is not necessarily characteristic of the asthma phenotype [28]. The authors therefore feel that, from a clinical perspective, most physicians would label these patients as having smokingrelated COPD, regardless of whether or not there is also partial $\beta_{2}$-agonist bronchodilator reversibility. Thus, it is likely that the results from the present study can be broadly generalised to other patients with clinically stable, physician-diagnosed COPD who are attending other outpatient clinics.

When the study protocol was developed, it was reasoned that a parallel-group randomised controlled trial would require a substantially greater number of study subjects in order to complete the study, and even then, as evidenced by a recent study by HUMBERT et al. [29], there is no guarantee that randomisation leads to matched study groups at baseline. The authors also carefully considered the merits of a randomised crossover study design but were aware of a number of potential methodological limitations that may be associated with such a design, including the uncertainty of the time needed for budesonide washout, which might have resulted in a treatment order effect. Thus, while they recognized the limitations of a single-blind sequential order study design $a$ priori, it was felt that a single-blind design was a methodologically acceptable approach to addressing this specific study question, particularly given that bias was removed by the sputum cell counts being performed in a double-blind fashion. The authors therefore decided to use a sequential, single-blind crossover study design, rather than a randomised two-period crossover design, because of the increased possibility of the confounding influence of infective exacerbations, the uncertainty regarding the maximum washout period of high-dose inhaled budesonide and the possibility of persistent clinical improvement beyond the active treatment period. The study was adequately powered to detect statistically significant differences in dyspnoea scores, quality of life and FEV1 measurements between the treatment groups at, or 
below, thresholds of what are regarded as minimally important clinical differences.

The results of this study support previous observations that measurements of quality of life in severe COPD are more sensitive to detecting changes in functional status than FEV1 [30-33]. The dyspnoea domain of the CRQ seems to be more discriminatory than the global score and could be more easily applied in practice. O'DonNELL et al. [34] have drawn attention to the importance of hyperinflation in patients with advanced COPD and that, when there is subjective improvement with little or no change in FEV1, there may be a reduction in hyperinflation identified by an increase in inspiratory capacity. This was not observed in the present study. Neither was any improvement in the 6-min walk test recorded. A possible reason for the small FEV1 improvement is that ICS cannot penetrate to more distal airways where much of the inflammation occurs. In this situation prednisone should be more effective. In the present study, this was assessed by adding an optional third period of prednisone treatment; in patients with sputum eosinophilia, prednisone treatment was associated with a seven-fold reduction in sputum eosinophil counts, compared to budesonide treatment, which was associated with only a three-fold reduction. This suggests that there may be a degree of inhaled steroid resistance in these patients, and the absence of apparent clinical benefit from a short burst of prednisone cannot necessarily be used to refute such an argument. Another reason for the small improvement in FEV1 is that the clinical improvement resulted primarily from reduction of the inflammatory component, as occurs in patients with eosinophilic bronchitis and without asthma.

The present study assessed the short-term effects of ICS treatment in patients with moderate-to-severe COPD. However, several large randomised, controlled trials have demonstrated that ICS treatment is associated with a reduction in the number of clinical exacerbations [5-7]. Therefore, clinicians prescribing ICS for patients with moderate-to-severe COPD are likely to do so with the expectation of preventing or reducing COPD exacerbations. In the context of this study, readers will be interested to note that the reduction in exacerbations seen with fluticasone in the Inhaled Steroids in Obstructive Lung Disease study was largely confined to subjects who had a good short-term response to corticosteroid treatment [35]. Thus, it is possible that the presence of sputum eosinophilia may, in addition to predicting short-term benefits from ICS treatment, also predict longer-term benefits, including the reduction of exacerbations.

Patients with smoking-related chronic airflow limitation were eligible for entry into the study provided they had an FEV1 $<60 \%$ pred; this cut-off was chosen as being the degree of physiological impairment at which patients with chronic airflow limitation might begin to experience symptoms of dyspneoa. As such, it was useful for such patients to be identified as being potentially suitable for this study. While the results from this study demonstrate the clinical benefit of budesonide treatment in patients with moderate-to-severe COPD and sputum eosinophilia, it provides no justification for the extension of the current COPD guidelines, which recommend that ICS in COPD only be initiated in patients when their FEV1 $<50 \%$ of predicted value.
The results of this study are important, since current guidelines do not recognise a predictor for clinical benefit of ICS treatment in patients with COPD [11, 15, 36-38]. They provide two potential reasons as to why previous large multicentre trials in COPD have failed to convincingly show clinical benefit from inhaled steroid treatment [3-7]. One reason is that they have not identified the subgroup of patients with eosinophilic bronchitis who will benefit from corticosteroid treatment. If the authors of this study had not done so, they would also have failed to identify improvement in CRQ or FEV1. The other reason for failure to show benefit in the multicentre trials is that they may have used too low a dose of inhaled steroid. It could be that the results of the present study underestimate the true benefit of inhaled budesonide in patients with moderateto-severe COPD. While the authors did not specifically discontinue ICS in otherwise eligible patients in order to qualify them for the study, it is possible that patients who had previously benefited from a trial of ICS were unlikely to have discontinued them, and thus they would not have been eligible for participation in this study.

While it is true that similar beneficial effects are seen in the great majority of patients treated with inhaled long-acting anticholinergics or long-acting $\beta$-agonists, the use if these agents in COPD is well accepted and forms the cornerstone of pharmacological therapy as recommended by current COPD guidelines [11, 36-38]. However, the guidelines are less clear in defining the role of ICS in COPD, perhaps in part because it is a heterogeneous condition, and there remains some debate as to which patients within this diagnostic group are likely to benefit significantly from the addition of ICS treatment. The aim of this study was to determine which phenotypes of patients with COPD are likely to benefit maximally from ICS therapy. Objective measurements of airway inflammation were applied to identify patients with COPD who would be likely to demonstrate a clinical response to ICS. The data indicate that patients with clinically stable COPD who have sputum eosinophilia should be treated with high-dose ICS, while those who do not have sputum eosinophilia $(\sim 60 \%)$ should not. Rather than promoting the widespread use of ICS in COPD, the present data suggests that using sputum eosinophilia as a predictor of inhaled steroid responsiveness is a valid approach to justify healthcare utilisation in COPD in an objective, evidenced-based approach.

Patients with sputum eosinophilia who showed clinical benefit from high-dose ICS were not necessarily those with frequent clinical exacerbations. In order to be eligible for entry into this study, patients needed to have been clinically stable for the preceding 8 weeks. Once randomised, the two patients who experienced a clinical exacerbation during the 10-week study period were discontinued from the study and their data was not included in the final analysis. The predictive benefit of budesonide in patients with sputum eosinophilia was nonetheless evident in patients who had been clinically stable for the 8 weeks prior to study entry, as well as for the 10 -week duration of the study.

In summary, about one-third of patients with clinically stable, moderate-to-severe smoking-related chronic obstructive pulmonary disease present with sputum eosinophilia. In the present study, this was associated with a clinically important 
response to high-dose inhaled budesonide therapy as measured by effects on dyspnoea during day-to-day activities. This improvement in dyspnoea (which could be measured in practice by the Chronic Respiratory Questionnaire dyspnoea domain) was associated with a small but statistically significant improvement in forced expiratory volume in one second (which may be easily missed in clinical practice) and in the global Chronic Respiratory Questionnaire score. Improvements in these outcome variables were paralleled by a significant reduction in sputum eosinophil counts to within the normal range in patients with sputum eosinophilia. The authors conclude that sputum eosinophilia predicts clinical benefit from inhaled high-dose corticosteroid treatment in patients with smoking-related moderate-to-severe chronic obstructive pulmonary disease, and that sputum cell counts are useful in the clinical management of these patients.

\section{ACKNOWLEDGEMENTS}

The authors would like to thank: the patients who participated in this study; L. Berman, S. Pugsley, G. Cox, A. Chterpensque and P. Moritz, for help with recruiting the patients; A. Efthimiadis, for supervising the examination of sputum and the quality control between centres; and S. Weston, S. Carruthers, S. Ferreira and M. Bélanger, for technical support.

\section{REFERENCES}

1 Calverley PM. Inhaled corticosteroids are beneficial in chronic obstructive pulmonary disease. Am J Respir Crit Care Med 2000; 161: 341-342.

2 Barnes PJ. Inhaled corticosteroids are not beneficial in chronic obstructive pulmonary disease. Am J Respir Crit Care Med 2000; 161: 342-344.

3 Paggiaro PL, Dahle R, Bakran I, Frith L, Hollingworth K, Efthimiou J. Multicentre randomised placebo-controlled trial of inhaled fluticasone propionate in patients with chronic obstructive pulmonary disease. International COPD Study Group. Lancet 1998; 351: 773-780.

4 Mahler DA, Wire P, Horstman D, et al. Effectiveness of fluticasone propionate and salmeterol combination delivered via the Diskus device in the treatment of chronic obstructive pulmonary disease. Am J Respir Crit Care Med 2002; 166: 1084-1091.

5 Calverley P, Pauwels R, Vestbo J, et al. Combined salmeterol and fluticasone in the treatment of chronic obstructive pulmonary disease: a randomised controlled trial. Lancet 2003; 361: 449-456.

6 Szafranski W, Cukier A, Ramirez A, et al. Efficacy and safety of budesonide/formoterol in the management of chronic obstructive pulmonary disease. Eur Respir J 2003; 21: 74-81.

7 Burge PS, Calverley PM, Jones PW, Spencer S, Anderson JA, Maslen TK. Randomised, double blind, placebo controlled study of fluticasone propionate in patients with moderate to severe chronic obstructive pulmonary disease: the ISOLDE trial. BMJ 2000; 320: 1297-1303.

8 Burge PS. EUROSCOP, ISOLDE and the Copenhagen city lung study. Thorax 1999; 54: 287-288.

9 Wedzicha JA. The heterogeneity of chronic obstructive pulmonary disease. Thorax 2000; 55: 631-632.
10 Lapperre TS, Snoeck-Stroband JB, Gosman MM, et al. Dissociation of lung function and airway inflammation in chronic obstructive pulmonary disease. Am J Respir Crit Care Med 2004; 170: 499-504.

11 National Collaborating Centre for Chronic Conditions. Chronic obstructive pulmonary disease. National clinical guideline on management of chronic obstructive pulmonary disease in adults in primary and secondary care. Thorax 2004; 59: Suppl. 1, 1-232.

12 Rennard SI. Treatment of stable chronic obstructive pulmonary disease. Lancet 2004; 364: 791-802.

13 Pizzichini E, Pizzichini MMM, Gibson P, et al. Sputum eosinophilia predicts benefit from prednisone in smokers with chronic obstructive bronchitis. Am J Respir Crit Care Med 1998; 158: 1511-1517.

14 Brightling CE, Monteiro W, Ward R, et al. Sputum eosinophilia and short-term response to prednisolone in chronic obstructive pulmonary disease: a randomised controlled trial. Lancet 2000; 356: 1480-1485.

15 Pauwels RA, Buist AS, Calverley PM, Jenkins CR, Hurd SS. Global strategy for the diagnosis, management, and prevention of chronic obstructive pulmonary disease. NHLBI/WHO Global Initiative for Chronic Obstructive Lung Disease (GOLD) Workshop summary. Am J Respir Crit Care Med 2001; 163: 1256-1276.

16 Fletcher CM, Elmes PC, Wood CH. The significance of respiratory symptoms and diagnosis of chronic bronchitis in a working population. BMJ 1959; 1: 257-266.

17 Pepys J. Skin tests in diagnosis. In: Gell PHG, Coombs RRD, Lachman PJ, eds. Clinical aspects of immunology. 3rd Edn. Oxford, Blackwell Scientific Publications, 1975; pp. 55-80.

18 Standardization of Spirometry, 1994 Update. American Thoracic Society. Am J Respir Crit Care Med 1995; 152: 1107-1136.

19 Guyatt GH, Berman LB, Townsend M, Pugsley SO, Chambers LW. A measure of quality of life for clinical trials in chronic lung disease. Thorax 1987; 42: 773-778.

20 Bourbeau J, Maltais F, Rouleau M, Guimont C. FrenchCanadian version of the Chronic Respiratory and St George's Respiratory questionnaires: an assessment of their psychometric properties in patients with chronic obstructive pulmonary disease. Can Respir J 2004; 11: 480-486.

21 Knox AJ, Morrison JF, Muers MF. Reproducibility of walking test results in chronic obstructive airways disease. Thorax 1988; 43: 388-392.

22 Redelmeier DA, Bayoumi AM, Goldstein RS, Guyatt GH. Interpreting small differences in functional status: the Six Minute Walk test in chronic lung disease patients. Am J Respir Crit Care Med 1997; 155: 1278-1282.

23 Pizzichini E, Pizzichini MMM, Efthimiadis A, et al. Indices of airway inflammation in induced sputum: reproducibility and validity of cell and fluid-phase measurements. Am J Respir Crit Care Med 1996; 154: 308-317.

24 Belda J, Leigh R, Parameswaran K, O’Byrne PM, Sears MR, Hargreave FE. Induced sputum cell counts in healthy adults. Am J Respir Crit Care Med 2000; 161: 475-478.

25 Crapo RO, Morris AH, Gardner RM. Reference spirometry values using techniques and equipment that meet ATS recommendations. Am Rev Respir Dis 1981; 123: 659-664.

26 Brightling CE, McKenna S, Hargadon B, et al. Sputum eosinophilia and the short term response to inhaled 
mometasone in chronic obstructive pulmonary disease. Thorax 2005; 60: 193-198.

27 Calverley PM, Burge PS, Spencer S, Anderson JA, Jones PW. Bronchodilator reversibility testing in chronic obstructive pulmonary disease. Thorax 2003; 58: 659-664.

28 Chanez P, Vignola AM, O'Shaugnessy $\mathrm{T}$, et al. Corticosteroid reversibility in COPD is related to features of asthma. Am J Respir Crit Care Med 1997; 155: 1529-1534.

29 Humbert M, Beasley R, Ayres J, et al. Benefits of omalizumab as add-on therapy in patients with severe persistent asthma who are inadequately controlled despite best available therapy (GINA 2002 step 4 treatment): INNOVATE. Allergy 2005; 60: 309-316.

30 Samet JM. Measuring the effectiveness of inhaled corticosteroids for COPD is not easy! Am J Respir Crit Care Med 2003; 168: 1-2.

31 Spencer S, Calverley PM, Sherwood BP, Jones PW. Health status deterioration in patients with chronic obstructive pulmonary disease. Am J Respir Crit Care Med 2001; 163: 122-128.

32 Jones PW, Willits LR, Burge PS, Calverley PM. Disease severity and the effect of fluticasone propionate on chronic obstructive pulmonary disease exacerbations. Eur Respir J 2003; 21: 68-73.
33 Celli BR, Cote CG, Marin JM, et al. The body-mass index, airflow obstruction, dyspnea, and exercise capacity index in chronic obstructive pulmonary disease. $N$ Engl J Med 2004; 350: 1005-1012.

34 O'Donnell DE, Revill SM, Webb KA. Dynamic hyperinflation and exercise intolerance in chronic obstructive pulmonary disease. Am J Respir Crit Care Med 2001; 164: 770-777.

35 Burge PS, Calverley PM, Jones PW, Spencer S, Anderson JA. Prednisolone response in patients with chronic obstructive pulmonary disease: results from the ISOLDE study. Thorax 2003; 58: 654-658.

36 Canadian Thoracic Society recommendations for the management of chronic obstructive pulmonary disease. Can Respir J 2004; 11: Suppl. B, 7B-59B.

37 Celli BR, MacNee W, ATS/ERS Task Force. Standards for the diagnosis and treatment of patients with COPD: a summary of the ATS/ERS position paper. Eur Respir J 2004; 23: 932-946.

38 American Thoracic Society/European Respiratory Society Task Force. Standards for the diagnosis and management of patients with COPD. Version 1.2. http://www. thoracic.org/copd/ Last updated: September 8, 2005. Last accessed: December 7, 2005. 